\title{
EL PRESBÍTERO COMO PEDAGOGO DE LA MISERICORDIA
}

DOI: https://doi.org/10.52039/seminarios.v62i216.144

\author{
José FÉlix GARcía BenAVENTE*
}

Iniciamos nuestra reflexión señalando que en la vida de la comunidad el sacerdote no es un mero facilitador, organizador, o manager, que tiene que desempeñar un gran número de tareas administrativas y cultuales, y cuando el tiempo se lo permite, dedicarse a acompañar a las personas y a los procesos pastorales. Su papel no es el de un simple dirigente. Él es el mediador-el puente-, es decir, quien debe siempre recordar que el Señor y Maestro «no ha venido para ser servido sino para servir» (cf. Mc 10, 45); que se inclinó para lavar los pies a sus discípulos (cf. Jn 13,5) antes de morir en la Cruz y de enviarlos por todo el mundo (cf. Jn 20, 21). Así el presbítero, comprometido en el cuidado del rebaño que pertenece al Señor, tratará de «proteger el rebaño, de alimentarlo y de llevarlo hacia Él, el verdadero buen Pastor que desea la salvación de todos. Alimentar el rebaño del Señor es, pues, ministerio de amor vigilante, que exige entrega total hasta el agotamiento de las fuerzas y, si fuera necesario, hasta el sacrificio de la vida» ${ }^{1}$.

Bastaría un pequeño examen cuantitativo para advertir ese gran desbalance que existe entre las múltiples tareas que realiza el presbítero y aquellas que verdaderamente corresponden con la naturaleza de su misión y están en orden a la consagración que ha recibido. Su ministerio pastoral está llamado a realizarlo entre las personas que se le han confiado, ser pastor y maestro en su comunidad, y no contentarse con delegar en otros la tarea de ser signo de la misericordia, basta pensar todo el trabajo que hoy se delega en los catequistas -casi únicos responsables de la formación en muchas parroquias-, en los líderes y animadores -en quien recae la tarea de la conducción de la comunidad, reservándose el presbítero los temas económicos-, y la tarea de los ministros extraordinarios de la comunión -quienes son hoy, en muchos lugares, los encargados de visitar y atender a los enfermos y a sus familiares-, por no

* Sacerdote de la diócesis de Torreón. Es doctor en filosofía por la Universidad Pontificia de México. Licenciado en Ciencias de la educación por la Pontificia Universidad Salesiana de Roma. Actualmente trabaja como docente, coordinador general de los Cursos de verano, y es el secretario académico del Instituto superior de ciencias religiosas.

1. Directorio para el ministerio y vida de los presbiteros, 25. 
hablar del trabajo de los responsables de Caritas a nivel parroquial-verdaderos apóstoles de la caridad-, y el presbítero ¿dónde está? Enfrascado en juntas y reuniones, limitándose al culto y a los sacramentales a fin de asegurar ingresos materiales.

¿Pero es ésta la tarea del sacerdote? ¿Nos ordenamos para ser administradores? ¿Y la cura de almas, el pastoreo, la predicación de la palabra, a qué se reducen? Recordemos que, ante todo, «habilitados, pues, por el carácter y por la gracia del sacramento del Orden, y hechos testigos y ministros de la misericordia divina, los sacerdotes de Jesucristo se consagran voluntariamente al servicio de todos en la Iglesia. En cualquier contexto social y cultural, en todas las circunstancias históricas. Los hombres desean encontrar en el sacerdote a un hombre de Dios, que diga con san Agustín: 'Nuestra ciencia es Cristo, y nuestra sabiduría es también Cristo. Él plantó en nuestras almas la fe de las cosas temporales, y en las eternas nos manifiesta la verdad'. Estamos en un tiempo de nueva evangelización: hay que saber ir en busca de las personas que se encuentran a la espera de poder encontrar a Cristo»².

Del texto anterior se destacan dos tareas fundamentales de la vocación sacerdotal: testigos y ministros de la misericordia, pero no solamente en el ámbito cultual o administrativo, sino en el marco de las circunstancias sociales que le impulsan a salir a buscar a las personas. Es interesante señalar que esta salida se propone desde la misericordia de Cristo, y no desde una determinada concepción teológica o pastoral, es decir, desde la naturaleza misma de Dios: ser testigos y ministros del Dios-misericordia.

Esta salida, de la que habla el Papa, quiere indicar que todo el ministerio pastoral del sacerdote requiere ser puesto al servicio del Pueblo de Dios, que no se preocupe tanto por aparecer como un líder, o un portador de grandes títulos académicos o de una retórica seductora, sino como «experto en humanidad, hombre de verdad y de comunión y como testigo de la solicitud del Único Pastor por todas y cada una de sus ovejas. La comunidad podrá contar, segura, con su disponibilidad, su obra de evangelización y, sobre todo, con su amor fiel e incondicionado. Manifestación de este amor será principalmente su dedicación en la predicación, la celebración de los sacramentos, en particular de la Eucaristía y del sacramento de la penitencia, y en la dirección espiritual, como medio para ayudar a discernir los signos de la voluntad de Dios. El sacerdote, por tanto, ejercitará su misión espiritual con amabilidad y firmeza, con humildad y espíritu de servicio, tendrá compasión de los sufrimientos que aquejan a los hombres, sobre todo de aquellos que derivan de las múltiples formas -viejas y nuevas- que asume la pobreza tanto material como espiritual. Sabrá también inclinarse con misericordia sobre el difícil e incierto camino de conversión de los pecadores, a los cuales reservará el don de la verdad y la paciente y alentadora benevolencia

2. Congregación para el Clero, El presbitero pastor y guía de la comunidad parroquial, 1. 
del Buen Pastor, que no reprocha a la oveja perdida, sino que la carga sobre sus hombros y hace fiesta por su retorno al redil (cf. Lc 15, 4-7)» ${ }^{3}$.

La tarea del presbítero es reproducir en sus entrañas, los mismos sentimientos de Cristo, de tal manera que pueda tocar con sus manos la carne de Cristo y ungir las heridas del que se encuentra maltrecho por el camino siguiendo el ejemplo del Buen Samaritano que baja de su cabalgadura (su dignidad y prestigio ante la comunidad) y se pone al mismo nivel del hermano, se inclina sobre él, lo cura, venda sus heridas y paga en la posada para que cuiden de él. «Gratuitamente hemos recibido y gratuitamente damos. Estamos llamados a servir a Jesús crucificado en cada persona marginada. A tocar la carne de Cristo en quien ha sido excluido, tiene hambre, sed, está desnudo, encarcelado, enfermo, desocupado, perseguido o prófugo» ${ }^{4}$.

Si bien, hay que recordar que cuando un laico, asumiendo existencialmente su compromiso bautismal y enviado por su comunidad asume una responsabilidad en la tarea evangelizadora, lo hace en función de su propio ser de bautizado y no como un delegado o un enviado más de un presbítero, o como a quien gentilmente se le da una oportunidad para que haga algo.

En nuestra reflexión, hay que indicar, que no se trata de señalar los límites de una cierta manera de concebir al sacerdote, ni de irse al extremo creando actitudes falsas o de pantalla, sino de recuperar una dimensión, que casi se ha olvidado en la vivencia del sacerdocio: ser verdaderos pedagogos al estilo de Jesús.

A partir de una lectura atenta del Evangelio advertimos que el estilo de vida de Jesús, y no solo sus enseñanzas, están inscritas en un contexto más amplio, en verdaderos comportamientos típicamente pedagógicos. «Él aparece no solo como maestro y pastor, sino también como verdadero pedagogo $»^{5}$, nosotros podríamos añadir, como pedagogo de la misericordia.

La de Jesús es una pedagogía divina, a ejemplo de su Padre Bueno, pero también una pedagogía humana encarnada en la situación concreta. Por una parte, Él se manifiesta como continuador de la pedagogía de Dios, quien se manifiesta a lo largo de la historia, «como un padre misericordioso, un maestro, un sabio que toma a su cargo a la persona -individuo y comunidad-en las condiciones en que se encuentra, la libera de los vínculos del mal, la atrae hacía sí con lazos de amor, la hace crecer progresiva y pacientemente hacia la madurez de hijo libre, fiel y obediente a su palabra» ${ }^{6}$.

Hay una verdadera pedagogía de Jesús que inicia con su encarnación, en la plenitud de los tiempos y llega a su culmen en el don de sí mismo. La pedagogía

3. Directorio para el ministerio y vida de los presbíteros, 41.

4. Papa Francisco, El nombre de Dios es misericordia. Una conversación con Andrea Tornielli, México 2016, 107.

5. A. Fallico, Pedagogia Pastorale. Questa sconosciuta. Itinerario di formazione per operatori pastorali. Presbiteri, religiosi e laici, Catania 2001, 305.

6. Directorio General para la Catequesis, 139. 
de Jesús es la de la entrega, la de la donación, la del perdón, la de la elección de sus discípulos, la de la misión, que tiene como meta mostrar a todos el amor incondicional del Padre y los valores del Reino. Para realizar su tarea Jesús se vale de diversos medios: "Con las palabras, signos, obras, los discípulos tuvieron la experiencia directa de los rasgos fundamentales de la 'pedagogía de Jesús': la acogida del otro, en especial del pobre, del pequeño, del pecador como persona amada y buscada por Dios; el anuncio genuino del Reino de Dios como Buena Noticia de la verdad y de la misericordia del Padre; un estilo de amor tierno y fuerte que libera del mal y promueve la vida; la invitación apremiante a un modo de vivir sostenido por la fe en Dios; la esperanza en el Reino y la caridad hacia el prójimo; el empleo de todos los recursos propios de la comunicación interpersonal, como la palabra, el silencio la metáfora, la imagen, el ejemplo, y otros tantos signos, como era habitual en los profetas bíblicos» ${ }^{7}$.

La pregunta que queda en el aire es ¿los presbíteros transmitimos la experiencia del amor del Padre misericordioso al estilo de Jesús, o hemos, con nuestra perversa creatividad, vaciado de fuerza y de riqueza el ministerio sacerdotal hasta hacerlo una sombra de lo que debería ser? No podemos ser verdaderos pedagogos de la misericordia, si primero no hemos sido verdaderos discípulos. Recuerda el papa Francisco «sólo quien ha sido tocado, acariciado por la ternura de la misericordia, conoce realmente al Señor» ${ }^{8}$.

Brevemente vamos a indicar algunos espacios y mediaciones que hacen visible el ministerio sacerdotal desde la pedagogía de la misericordia. Lo primero que indicamos es que no hay que tenerle miedo a que nos llamen catequistas. Algunos sacerdotes se sienten ofendidos cuando les preguntan si son catequistas, como que sienten que son rebajados. El mismo Directorio General para la Catequesis nos recuerda que «la función propia del presbítero en la tarea catequizadora brota del sacramento del Orden que ha recibido. 'Por el sacramento del Orden, los presbíteros se configuran con Cristo sacerdote, como ministros de la Cabeza, para construir y edificar todo su Cuerpo que es la Iglesia, como cooperadores del orden episcopal'. Por esta ontológica configuración con Cristo, el ministerio de los presbíteros es un servicio configurador de la comunidad, que coordina y potencia los demás servicios y carismas. En relación con la catequesis, el sacramento del Orden constituye a los presbíteros en 'educadores en la fe'. Tratan, por ello, de que los fieles de la comunidad se formen adecuadamente y alcancen la madurez cristiana. Sabiendo, por otra parte, que su 'sacerdocio ministerial' está al servicio del 'sacerdocio común de los fieles', los presbíteros fomentan la vocación y la tarea de los catequistas, ayudándoles a realizar una función que brota del Bautismo y se ejerce en virtud de una misión que la Iglesia

7. Directorio general para la catequesis, 140 .

8. Papa Francisco, El nombre de Dios es misericordia. Una conversación con Andrea Tornielli, México 2016, 53. 
les confía. Los presbíteros llevan a cabo, de esta manera, la recomendación del Concilio Vaticano II, cuando les pide que 'reconozcan y promuevan la dignidad de los laicos y la parte que les corresponde en la misión de la Iglesia'»`.

\section{SER VERDADEROS EDUCADORES EN LA MISERICORDIA}

Siguiendo la estructura del Catecismo de la Iglesia Católica, que será fuente, junto con la Sagrada Escritura y la Tradición viva de la Iglesia, de su tarea pedagógica, indicamos algunas intuiciones sobre la pedagogía de la misericordia.

\section{a) Primera parte: La profesión de fe}

Hoy se propone transmitir una visión renovada del misterio de Dios Padre bueno rico en misericordia. Del Dios compasivo y misericordioso de las Escrituras. Una fe que se hace profesión comunitaria, que se vive, se enseña, se transmite y se celebra en lo concreto de la vida eclesial y de las personas. Se trata de pasar de una recitación a una experiencia, sin negar que algo debe quedar en la memoria. Cuando predicamos, cuando estamos con los niños de la catequesis, si es que llegamos a estar, cuando preparamos -juntos con los catequistas- a los que piden un sacramento, de qué Dios les hablamos, de un Dios vengador y justiciero que castiga o les hablamos de que lo importante, en la vida de cada hombre y de cada mujer, no es no volver a caer jamás en el camino; lo importante es levantarse siempre, no quedarse en el suelo lamiéndose las heridas. El Señor de la misericordia me perdona siempre, de manera que me ofrece la posibilidad de volver a empezar siempre. Me ama por lo que soy, quiere levantarme, me tiende su mano. El Papa insiste en que es también una tarea de la Iglesia el hacer saber a las personas que no hay situaciones de las que no se puede salir, que mientras estemos vivos es siempre posible volver a empezar, siempre y cuando permitamos a Jesús abrazarnos y perdonarnos $»^{10}$.

El mismo Catecismo, al explicarnos el nombre de Dios en el inicio del Credo, nos enseña que: «El Nombre divino 'Yo soy' o 'Él es' expresa la fidelidad de Dios que, a pesar de la infidelidad del pecado de los hombres y del castigo que merece, 'mantiene su amor por mil generaciones' (Ex 34, 7). Dios revela que es 'rico en misericordia' (Ef 2, 4) llegando hasta dar su propio Hijo» ${ }^{11}$.

Desde su propia naturaleza, su ser, su "Yo soy», brota la naturaleza íntima de Dios que debería de ser uno de los núcleos de la catequesis en todas sus dimensiones en cuanto a contenidos, destinatarios, agentes, formas y etapas: Dios es rico en misericordia, o en palabras del papa Francisco «porque es Dios,

9. Directorio, 224.

10. Papa Francisco, El nombre de Dios, 72.

11. Catecismo, 211. 
porque Él es misericordia, y porque la misericordia es el primer atributo de Dios. Es el nombre de Dios $»^{12}$. Desde ésta perspectiva, qué distintas serían nuestras catequesis cuando enseñamos las verdades de nuestra fe.

\section{b) Segunda parte: Los sacramentos de la fe}

Una de las expresiones más ricas en las que queda patente la misericordia divina son precisamente la celebración de los sacramentos, las cuales de modo paradigmáticos encierran grandes antinomias. Por ejemplo:

-Es a las celebraciones litúrgicas a las que más tiempo le dedica un presbítero, pero ese tiempo no corresponde necesariamente con una adecuada preparación ni del celebrante, ni de los que celebran, ni de lo celebrado.

-Fácilmente se cae en ritualismos y celebraciones a la carrera, a veces marcadas por la impaciencia y la descortesía, dándose situaciones que lastiman y hieren a la comunidad.

-Celebraciones de la gratuidad de Dios, pero que están marcadas por costos y aranceles, expresando muchas veces una iglesia de primera y una iglesia para el resto.

-Celebraciones que pueden ser momento de acogida, de acercamiento y que sin embargo terminan solo marcando más la exclusión y la marginación, generando en muchos el punto de quiebre de inserción a la comunidad.

La celebración de la fe es un momento privilegiado para que el presbítero como pedagogo acuda a la riqueza mistagógica de la Iglesia y permita a la comunidad ser introducida en el misterio de Dios que se celebra. "La catequesis litúrgica pretende introducir en el Misterio de Cristo (es «mistagogia»), procediendo de lo visible a lo invisible, del signo a lo significado, de los «sacramentos» a los 'misterios'»' ${ }^{13}$. La perspectiva del celebrante no debe ser solo la de cumplir un rito, sino actualizar el misterio de salvación en el aquí y ahora de la historia, y al mismo tiempo, por la fe que se celebra, introducir a los creyentes en los misterios de salvación.

\section{Una palabra sobre algunos sacramentos}

La Eucaristía debería de ser para todos «Misterio grande, Misterio de misericordia. ¿Qué más podía hacer Jesús por nosotros? Verdaderamente, en la Eucaristía nos muestra un amor que llega «hasta el extremo» (Jn 13, 1), «un amor que no conoce medida» (Ecclesia de Eucharistia, 11). Es precisamente en el contexto de la primera comunión que el común de nuestros fieles recibe una

13. Catecismo, 1075. 
mayor y sistemática preparación, y habría que decir, que en algunos casos la única preparación. Esta situación se presenta como un reto y una gran oportunidad para rescatar una profunda teología del símbolo, introduciendo a los pequeños en la dimensión simbólica de la liturgia, explicando los gestos, las acciones, los momentos, más que estar preocupados por el orden y el silencio.

La misma celebración se convierte en un espacio y mediación pedagógica para ir explicando los signos, para iniciar a la participación, pero no de un rito, sino del gran gesto de la misericordia de Jesucristo, que se entregó por amor y nos liberó del pecado y de la muerte. Cuánto enseña a una comunidad un sacerdote que celebra con alegría la eucaristía, sin prisas, ni afectaciones, sin estridencias, respetando el ritmo celebrativo, preparando lo necesario con sus colaboradores y enseñando a contemplar en el silencio el misterio eucarístico al verlo entrar en esa dimensión. No basta con preparar la homilía, si bien ella es la catequesis litúrgica por excelencia, no basta, es necesario contextualizarla en el cuerpo armónico de la celebración eucarística.

Pensemos en esta misma línea el valor pedagógico que tiene para un enfermo y su familia, cuando es el mismo sacerdote, y no sus delegados o ministros extraordinarios, el que visita al enfermo, el que le lleva la comunión como expresión del amor misericordioso por los más débiles y vulnerables. Para un enfermo esa visita se convierte en un verdadero momento salvífico, pues es la Iglesia, en la persona del presbítero, la que se hace presente, por no decir lo que significa para muchas personas que «su enfermo» sea visitado, conformado, acompañado por el pastor de la comunidad. Se convierte en una verdadera catequesis de la misericordia eucarística.

El sacramento de la reconciliación es precisamente la misericordia en acto de parte de Dios para con el pecador. El papa Benedicto recordaba que «es preciso volver al confesionario, como lugar en el cual celebrar el sacramento de la Reconciliación, pero también como lugar en el que 'habitar' más a menudo, para que el fiel pueda encontrar misericordia, consejo y consuelo, sentirse amado y comprendido por Dios y experimentar la presencia de la Misericordia divina, junto a la presencia real en la Eucaristía» ${ }^{14}$.

Cómo enseñarle al pueblo santo de Dios a confesarse si no hay confesores, si no tenemos tiempo para escucharlos, para desarrollar lo que llama el papa Francisco la pastoral de la oreja, «las personas buscan sobre todo a alguien que las escuche. Alguien dispuesto a dar su propio tiempo para escuchar sus dramas y sus dificultades $»^{15}$. Para poder ser un verdadero pedagogo de la confesión habrá que acudir frecuentemente nosotros mismos al confesionario, para

14. Benedicto XVI, Discurso a los participantes en el XXI Curso sobre el Fuero interno organizado por la Penitenciaría apostólica, 11 de marzo de 2010.

15. Papa Francisco, El nombre de Dios, 38. 
experimentar nuestro límite y aprender la misericordia que vamos a comunicar, pues «confesarse con un sacerdote es un modo de poner mi vida en las manos y en el corazón de otro (en nuestro caso en las manos y corazón de otro sacerdote), que en ese momento actúa en nombre y por cuenta de Jesús» ${ }^{16}$.

La experiencia de la misericordia se convierte en un parámetro de la fidelidad de la Iglesia a su propia misión, pues ella «vive una vida auténtica, cuando profesa y proclama la misericordia -el atributo más estupendo del Creador y del Redentor- y cuando acerca a los hombres a las fuentes de la misericordia del Salvador, de las que es depositaria y dispensadora. De frente a una concepción secularizada de la misericordia, que no logra transformar el interior del hombre, la misericordia de Dios ofrecida en la Iglesia se presenta como perdón y como medicina saludable ${ }^{17}$.

El magisterio recuerda que como presbíteros somos jueces y médicos, llamados a la disponibilidad ${ }^{18}$, pero también pedagogos del perdón de Dios si enseñamos, no solo el catálogo de los pecados, sino la misericordia de Dios que nos perdona y el camino de conversión que se nos propone al celebrar la reconciliación. Pues «el sacerdote es ministro, es decir, siervo y a la vez administrador prudente de la divina Misericordia. A él queda confiada la gravísima responsabilidad de «perdonar o retener los pecados» (cf. Jn 20, 23); a través de él, los fieles pueden vivir, en el presente de la Iglesia, por la fuerza del Espíritu, que es el Señor y da la vida, la gozosa experiencia del hijo pródigo, el cual, cuando regresa a la casa del padre por vil interés y como esclavo, es acogido y reconstituido en su dignidad filial» ${ }^{19}$.

En el sentido pedagógico hay que recordar que es necesaria una profunda preparación del ministro para la adecuada acogida, escucha, acompañamiento y orientación del penitente. "Por tanto, es necesario que [el presbítero], además de una buena sensibilidad espiritual y pastoral, tenga una seria preparación teológica, moral y pedagógica, que lo capacite para comprender la situación real de la persona. Además, le conviene conocer los ambientes sociales, culturales y profesionales de quienes acuden al confesionario, para poder darles consejos adecuados y orientaciones espirituales y prácticas. Además de la sabiduría humana y la preparación teológica, es preciso añadir una profunda vena de espiritualidad, alimentada por el contacto orante con Cristo, Maestro y Redentor» ${ }^{20}$.

16. Ibid., 42.

17. Congregación para el Clero, El presbítero, maestro de la palabra, ministro de los sacramentos y guía de la comunidad ante el tercer milenio cristiano, IV, 1.

18. Congregación para el Clero, El Sacerdote confesor y director espiritual, ministro de la misericordia divina, 21. 59.

19. Congregación para el clero, El sacerdote, confesor, Presentación.

20. Benedicto XVI, Discurso a los Penitenciarios (19 de febrero de 2007); cf. también el discurso del 7 de marzo de 2008. 
Cuánto bien hace a una comunidad y qué gran enseñanza cuando ve que su párroco o su vicario también se confiesa, que el sacerdote ante su pecado también acude a la misericordia, como él exhorta y enseña a la comunidad. Cuánto aprende una persona cuando es tratada con respeto y dignidad en el confesionario, cuando ante su pecado se le ofrecer la misericordia y la vía de la conversión. «A los sacerdotes les recuerdo, dice el papa, que el confesionario no debe ser una sala de torturas sino el lugar de la misericordia del Señor que nos estimula a hacer el bien posible» (Evangelii Gaudium, 44).

La pedagogía de la misericordia habrá que desdoblarla en la pedagogía de la escucha y de la acogida, en la pedagogía del encuentro, en la pedagogía de quien se sabe perdonado y enseña a otros a perdonar, en la pedagogía de la alegría por la oveja perdida y encontrada. Es decir «los confesores están llamados a abrazar ese hijo arrepentido que vuelve a casa y a manifestar la alegría por haberlo encontrado» (Misericordiae vultus, 17).

El sacramento de la Unción de los enfermos se enmarca en la condición del límite humano y de la enfermedad, son momentos privilegiados para vivir y recibir la misericordia de parte de Dios. Con cuánta dificultad hoy se logra que un presbítero visite un enfermo o un hospital. En ciertos casos lo hace de la manera más discreta y rápida para no ser reconocido por otros enfermos y la solicitud de unciones se prolongue. En muchos ambientes son los laicos los que visitan hospitales, asilos y casas particulares donde están los enfermos. Y es ahí en donde la pedagogía de la misericordia se hace signo creíble para ese enfermo, para esa familia, pues para ellos la misericordia de Dios toca a su enfermo, lo alienta y lo conforta. La pedagogía litúrgica se hace caridad cuando no solo se le unge, sino se le atienden las necesidades del cuerpo y del estómago. Cuando se le ayuda de modo concreto en sus necesidades. Ahí se aprende que Dios es Padre Bueno y que no abandona a sus hijos, que la comunidad creyente vive el testimonio concreto de la caridad, y es ahí donde el sacerdote se convierte en padre de los enfermos y necesitados. Qué bueno si hay laicos que visitan a los enfermos, pero eso no exime al sacerdote de su compromiso y testimonio, y que sencilla lección cuando al atender a un enfermo enseñamos que no se cobra por servir.

\section{c) Tercera parte: La vida de fe}

En el marco del año de la misericordia el Santo Padre Francisco nos ha recordado verdades tan antiguas como el Evangelio mismo: las obras de misericordia, que son de manera sencilla y práctica modos concretos de vivir la misericordia. En este campo la acción pedagógica del presbítero es fundamental en dos sentidos, el primero abriendo espacios para el compartir, el salir, el ayudar, y segundo, acompañando dichos procesos de caridad y solidaridad. 
Muchos jóvenes encuentran en el servicio y el trabajo voluntario una forma de iniciarse en la solidaridad, descubren canales concretos para la organización, la toma de conciencia y el compromiso específico en el campo de la promoción de la persona. Sin embargo, hoy en día un grupo juvenil parroquial no entusiasma tanto como el organizarse en una determinada causa social, pues «los jóvenes, en las estructuras habituales, no suelen encontrar respuestas a sus inquietudes, necesidades, problemáticas y heridas» (Evangelii Gaudium [= EG] 105). Se trata de un campo privilegiado para que el presbítero salga de su zona de confort y se involucre de manera activa junto a los demás, para «salir de la propia comodidad y atreverse a llegar a todas las periferias que necesitan la luz del Evangelio» (EG 20). Pensemos como numerosos laicos, que hace años eran miembros de grupos y asociaciones religiosas, ante el nulo compromiso social de muchos de ellos, prefirieron integrarse en clubes de servicio y hoy son parte fundamental de organizaciones no gubernamentales, y son portadores de un bagaje de doctrina social, que recibieron en sus asociaciones, pero al no encontrar espacios para el compromiso social emigraron a otros horizontes. Los laicos organizados son grandes aliados para el trabajo común de la Iglesia.

En este campo del servicio y de la caridad la pedagogía de la misericordia se expresa bajo una pedagogía social que invita a «mirar las miserias del mundo, las heridas de tantos hermanos y hermanas privados de la dignidad, [y provocan] escuchar su grito de auxilio» (MV 15). En este sentido se trata no de volver a delegar en otros las tareas y la presencia en la periferia, sino de la pedagogía del compartir, del encuentro, del estar ahí en donde nadie está, y llegar a ser una auténtica presencia eclesial. Pues para «la Iglesia la opción por los pobres es una categoría teológica antes que cultural, sociológica, política o filosófica» (EG 198).

La Congregación del Clero en el documento del 2001, El presbítero pastory guía de la comunidad parroquial, número 22, indicaba: «Educar en la práctica de las obras de misericordia espirituales y corporales constituye una prioridad pastoral, y es signo de vitalidad en una comunidad cristiana». No se trata por tanto de dedicar las sobras del tiempo a la pastoral social, sino de socializar la pastoral, de tal manera que toda acción eclesial tenga una prolongación en ese salir a las periferias existenciales. Se trata de una auténtica pedagogía de la misericordia, pues, «el imperativo de escuchar el clamor de los pobres se hace carne en nosotros cuando se nos estremecen las entrañas ante el dolor ajeno» (EG 193).

Cuánto bien le hace a una comunidad cuando ve a su párroco salir a visitar a los que nadie visita, a los descartados de la sociedad, y está ahí con ellos. Qué distinto es enviar que ir, qué distinto es conseguir ayuda que compartir lo propio; esta es precisamente la pedagogía de la caridad que hoy traduce la misericordia del Padre. 


\section{d) Cuarta parte: La oración en la vida de la fe}

Se trata de una de las pedagogías más exquisitas a las que está llamado el presbítero. Como ministro de la misericordia el presbítero está llamado a vivir en el diálogo fecundo con Dios que lo hace anhelar en su ministerio esa misericordia de la que es servidor. «Así, pues, los sacerdotes deben considerarse como signos vivientes y portadores de una misericordia que no ofrecen como propia, sino como don de Dios. Son sobre todo servidores del amor de Dios por los hombres, ministros de la misericordia» ${ }^{21}$.

La pedagogía de la misericordia pasa por la oración creyente del propio presbítero. Cómo hablar de alguien que no conoce, se corre el riesgo de convertirse en funcionario, en empleado, cuando su tarea es la de testigo.

De la sólida unidad entre Cristo y su ministro, realizada en el Espíritu Santo, desechando toda pretensión, por parte del ministro, de sustituir a Cristo, sino apoyándose en Él y dejándole obrar en su persona y a través de su persona, depende también hoy la obra eficaz de la misericordia divina contenida en la Palabra y en los sacramentos. También a esta conexión del sacerdote con Jesús se extiende el contenido de las palabras: "Yo soy la vid. Como el sarmiento no puede dar fruto por sí mismo si no permanece en la vid, así tampoco vosotros si no permanecéis en mí» $(\mathrm{Jn} 15,4)^{22}$.

La experiencia de la misericordia se nutre de la propia experiencia de contemplación, «así es la misericordia de Dios: una gran luz de amor, de ternura, porque Dios perdona no con un decreto, sino con una caricia» ${ }^{23}$. Se trata de experimentar a Dios como el Padre de la misericordia que sale en búsqueda del hijo que se ha ido, como el buen samaritano que se inclina sobre el hombre herido, así también el presbítero ha de vivir la pedagogía de la oración. Evocando su experiencia como obispo en Argentina, el Papa recordaba la oración de un confesor ante el tabernáculo: «Señor, perdóname porque he perdonado demasiado. ¡Pero eres Tú el que me ha dado un mal ejemplo! [...] Cuando un sacerdote vive así la misericordia sobre sí mismo, puede regalársela a los demás ${ }^{24}$.

Uno de los riesgos es copiar diversas prácticas de espiritualidad o de imponer a la comunidad determinadas formas de orar. Alguien decía que el laico vive una espiritualidad a la intemperie, que no hay una espiritualidad para él y tiene que andar buscando cobijo en espiritualidades «prestadas» propias de religiosos o clérigos. Qué distinto cuando el presbítero, como pedagogo de la oración, vive su propia experiencia orante y anima a otros a vivir su propio itinerario espiritual. No

21. Congregación para el Clero, El presbitero, maestro de la palabra, ministro de los sacramentos y guía de la comunidad ante el tercer milenio cristiano, IV, 2.

22. Congregación para el clero, El presbítero, maestro, IV, 2.52.

23. Papa Francisco, El nombre de Dios es misericordia, México 2016, 17.

24. Ibid., 35. 
se trata solo de orar por la unidad de sus fieles, sino de orar junto con sus fieles, a veces no se trata de decir nada, sino tan solo de estar ahí con ellos.

A través del misterio de Cristo, el sacerdote, ejercitando su múltiple ministerio, está insertado también en el misterio de la Iglesia, la cual «toma conciencia, en la fe, de que no proviene de sí misma, sino por la gracia de Cristo en el Espíritu Santo». De tal manera, el sacerdote, a la vez que está en la Iglesia, se encuentra también ante ella.

La expresión eminente de esta colocación del sacerdote en la Iglesia y ante la Iglesia, es la celebración de la Eucaristía donde «el sacerdote invita al pueblo a levantar el corazón hacia el Señor en la oración y la acción de gracias, y lo une a sí en la solemne oración, que él, en nombre de toda la comunidad, dirige a Dios Padre por medio de Jesucristo en el Espíritu Santo» (Directorio, 13).

Cuánto bien le hace a una comunidad cuando ve a su pastor orar, suplicar para él y para todos, la misericordia de Dios. Entrar en un templo y ver al sacerdote orar es hoy algo cada vez más extraño, cuando tendría que ser uno de los signos de la pedagogía de la misericordia. Quien ama a su pueblo constantemente está pidiendo misericordia para todos.

\section{AMODO DE CONCLUSIÓN}

La misericordia de la que el presbítero es testigo y ministro requiere formas nuevas de una pedagogía de la misericordia, que, partiendo de la propia experiencia de ser amado y perdonado, lleva a la comunidad a esa misma fuente de vida, el amor misericordioso del Padre que, en Jesús, por la fuerza del Espíritu Santo, nos ha perdonado y nos ha reconciliado.

Es volver a la pedagogía del signo, en donde la vida misma del presbítero se torna en la mediación pedagógica más elocuente, que habla sin decir, y que congrega y une a la comunidad. Se trata de rescatar la dimensión mistagógica que introduce en el misterio del amor misericordioso de Dios a todos. 